ever, has written his thanks to each person for the 198 postcards of libraries which he received. Twenty-four of the cards were of interiors, with the most exquisite gift being ten photocards of the Sterling Library at Yale University from Gay Walker, curator of the arts of the Book (see Fig. 1 for one of the more active and probably the innermost of the cards: the fountain in the Yale Librarian's Courtyard). She and the other donors are also thanked publicly for their largess with such gems as the "Nyack Public Library, Nyack on the Hudson, New York," framed in living color with lovely blue forget-me-nots; and the "Rosenberg Day, Rosenberg Library, Galveston, Texas" postcard with many citizens and their children proudly posed in front of the building. Public thanks are also grate- fully extended to two continuing donors of many postals: Frederick Duda and James Davis.

\section{Second plea}

As announcers on radio programs continually repeat: "Keep those cards and letters coming!" The author asks for more. He received cards and letters from old and new friends along with library postcards. He continues to welcome postcards (academic interior or exterior), questions and comments mailed to him at the Kuhn Library and Gallery, UMBC, Baltimore, MD 21228. He again promises to send you a library postcard in return, but probably not an interior.
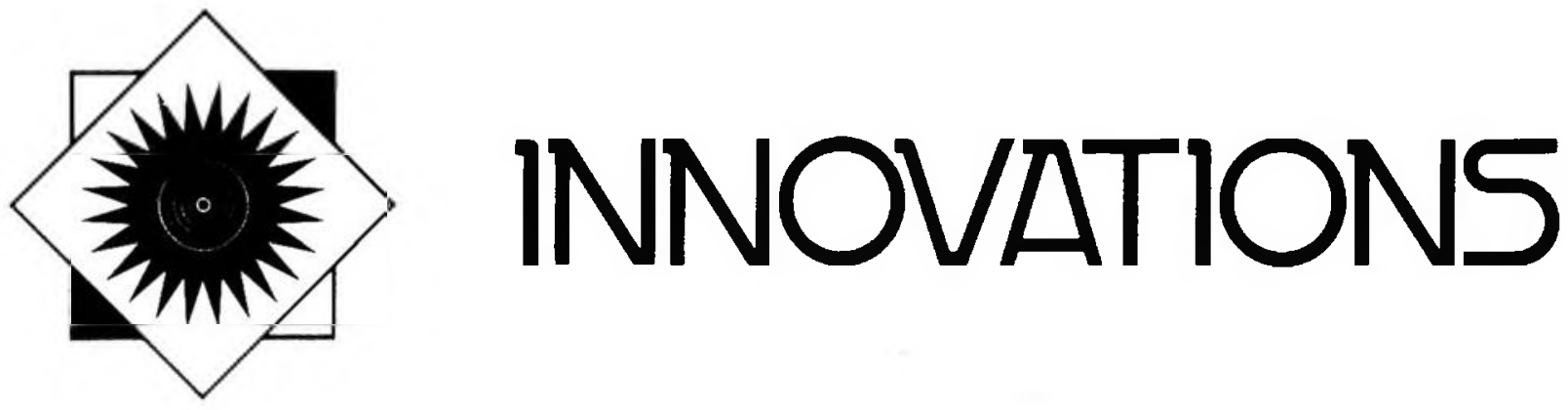

\title{
Student pre-surveys as bibliographic instruction tools
}

\author{
By Tony Amodeo \\ Bibliographic Instruction Coordinator \\ Loyola Marymount University
}

It happens again and again to every BI librarianlecturer: "Who is my audience? To whom am I talking?" You are called in on relatively short notice-yes, policy says "two weeks advance notice," but when your mission is to reach as many students as possible, you almost always give in. You know you will be faced with a jumble of lower and upper division students, some of whom have had the orientation tour, the freshman library lecture, and perhaps one or two presentations in their other classes, some of whom have not known there was a library on campus-or so it seems. You try to pump the teacher for information, but this one is the type that is almost never reachable on campus, and who sends a student assistant with a scribbled note that they want a library lecture on the day they will be in Fredericton, N.B., for a conference.

At such moments, a good solution may be to hand to the student assistant a stack of short but well thought-out survey forms to be given to the class, filled out, collected and sent to you by the teacher or the assistant. Such a form can be of help in a number of ways.

With a little thought, the survey can warm up the class to a library lecture. It can let them identify some of the issues you will address, and some aspects of the library to begin thinking about. A survey can request feedback on problems encountered in the library, employing a list of possible problems to be ticked off, plus room for comments and suggestions. It can also solicit their expectations and their "wish-lists" regarding the material to be covered, which can be very helpful in designing the lecture for this specific audience.

Answers from the survey can tell you a lot about the level of library understanding in the class, e.g., whether or not the students have had previous lectures, a tour, or no presentation at all; what level of 
library experience/understanding the students have, as well as the major areas of insecurity or concern for individual students.

Survey answers can also tell you, directly or indirectly, some useful things about your library. For example, if students can't find the reference desk, is signage adequate? Should there be a better map of the library? If students feel ignored even if they ask for help, is overall service what it should be? Are student assistants misdirecting people? Are there some personnel who are less than helpful? Should instructions for automated equipment, the cata$\log$, individual service locations be more clear?

In an anonymous survey, students often tell you more than you asked to know; comments often come more from personal feelings and individual experiences than as a direct answer to your survey questions. You may also begin to identify faculty who give the library short shrift or bad press, since students often absorb teachers' peeves and biases by osmosis. Such evidence can be useful in spurring some action on the part of the library to address faculty problems - or problem faculty. Sometimes a simple update will do; sometimes re-education may be necessary, especially for some who have not gotten any of your library's dust on their feet since the last revision of their lecture notes twenty years ago.

Careful writing of the survey can give forth statistics useful to the BI program, and to the library as a whole. If a computer program were written to correlate elements of the individual survey forms, good statistical evidence supporting a BI program might emerge. For example, the number and type of problems encountered could be correlated to the number, level, or absence of previous BI lectures or tours; student level might be correlated with attitude, evaluation of lectures, or type of problems encountered. [If anyone has, and is willing to share such a computer program, please let me-and the editor of $C \Downarrow R L$ News-know!]

Of course, anonymous surveys and evaluations have their drawbacks; some students will tell things on an anonymous written form that they would never tell in person - which obviously has its repercussions in the form of spurious, comic, or deviant comments. But sometimes students have creative insights that can cut through academic insulation - and that fog of professional prejudiceby-habit.

Best of all, using a survey's results at the beginning of your lecture is a good way to gain confidence (you're not coming at them cold); to get attention; to give the class the feeling (one would hope, based in reality) that you care about their individual problems; and to keep them listening for the solution to the problem they wrote aboutwhich your talk probably would have addressed in any case, but which now is perceptively tailored to your audience as individuals.

\title{
Innovative use of in-house current awareness profiles as a guide for collection development in a pharmaceutical library
}

\author{
By Daniel T. Law \\ Senior Information Specialist \\ Smith Kline \& French Laboratories, King of Prussia, Pa.
}

If the basic tenor of collection development (CD) is the identification and procurement of resources in support of current and anticipated patron needs, then it becomes the primary responsibility of the CD librarian to first assess those needs, and then to select and acquire resources for the meeting of those needs. However, CD librarians are often met with distrust, particularly from faculty colleagues who often are mildly suspicious of their qualifications as "book selectors" ("Are they really qualified?"), or their "methods of selection" ("How do they choose their books anyway?"). The problem stems largely from the imprecise nature of their work. Granted, CD is not an exact science; but it need not become an entirely subjective and arbitrary undertaking either.

Perhaps what is needed is a heightened awareness on the part of collection developers to put CD on a more objective and "scientific" foundation. Such a feat is not as impossible as it may appear. Collection development has at least two attributes which qualify it as "scientific." They are: controllability and quantifiability. Collection development is controllable, to the extent that its activities can be efficiently directed towards the attainment of desired objectives. ${ }^{1}$ It is quantifiable, because

${ }^{1}$ R. L. Ackoff, et al., Scientific Method: Optimizing Applied Research Decisions (New York: John Wiley \& Sons, 1962), 3. 